DOI: https://doi.org/10.47405/mjssh.v6i9.1011

\begin{tabular}{|c|c|}
\hline 4.581 & Malaysian Journal of Social Sciences and Humanities (MJSSH) \\
\hline $\begin{array}{l}\text { Malaysian Journal of } \\
\text { socal s ciences and }\end{array}$ & Volume 5, Issue 8, August 2020 \\
\hline (MJ-SSH) & e-ISSN : 2504-8562 \\
\hline & $\begin{array}{l}\text { Journal home page: } \\
\text { www.msocialsciences.com }\end{array}$ \\
\hline
\end{tabular}

\title{
Time Series Analysis and Forecasting Techniques for Foreign Direct Investment
}

\author{
Ummi Rohaizad Abdul Rahim ${ }^{1,3}$, Zahayu Md Yusof 1,2 \\ 15chool of Quantitative Sciences, Universiti Utara Malaysia 06010 UUM Sintok, Kedah, Malaysia \\ ${ }^{2}$ Institute of Strategic Industrial Decision Modelling, School of Quantitative Sciences, \\ Universiti Utara Malaysia, 06010 UUM Sintok, Kedah, Malaysia \\ ${ }^{3}$ RBC Investor and Treasury Services, Royal Bank of Canada, 63000 Cyberjaya, Selangor, Malaysia \\ Correspondence: $\underline{\text { ummirohaizadrahim@gmail.com }}$
}

\begin{abstract}
Foreign direct investment are the net inflows of investment to acquire a lasting management interest which is 10 percent or more of voting stock in an enterprise operating in an economy other than the investor. It is the sum of equity capital, reinvestment of earnings, other long-term capital, and shortterm capital as shown in the balance of payments. This paper will discuss the definitions and findings of previous studies regarding Foreign Direct Investment. This paper also will explain about forecasting techniques used in previous studies in forecasting Foreign Direct Investment. Time Series Analysis is used to determine a good model that can be used to forecast business metrics.
\end{abstract}

Keywords: foreign direct investment, time series analysis, forecasting

\section{Introduction}

Foreign Direct Investment (FDI) is an investment by a party from other country into the local company or local business of the country with the intention of creating a lasting interest. For example, a party from United States invest in a local business of Malaysia. The long-term interest rate distinguishes FDI from foreign portfolio investments, where investor is passively holding the foreign securities. FDI can be made by acquiring a lasting interest of developing its activity to other country (James, 2021).

Since 2010, foreign investment in Malaysia has been oscillating between USD 9 billion and USD 12 billion, making the country one of the highest recipients of FDI in the region. Besides, according to UNCTAD's World Investment Report in 2020, FDI inflows in Malaysia decreased during the last two years, which is reaching USD 7.6 billion in 2019. FDI stock was about USD 169 billion in 2019. Multinationals in the Mergers and acquisitions (M\&A) sector, such as those in the health and mining sectors have sustained the level of investment. Based on the data from the Malaysian Investment Development Authority (MIDA) in 2020, majority of investments came from Singapore, Hong Kong, Japan and Netherlands were directed towards manufacturing, financial and insurance activities, and mining and quarrying.

According to the Ministry of Finance of Malaysia, FDI stock rose by $10.3 \%$ to USD 163.8 billion in the second quarter of 2019. According to UNCTAD's latest Global Investment Trends Monitor released on 27 October 2020, Global foreign direct investment (FDI) flows fell $49 \%$ worldwide in the first half of 2020 compared to 2019, and 20\% in South East Asia. In this global context, Malaysia's FDI 
inflow is projected to come in at RM 16 billion (USD 3.92 billion) to RM17 billion (USD 4,17 billion) in 2020, a drop from RM 37.5 billion (USD 9,20 billion) in 2019 or a fall of between $-54.6 \%$ to $-57.3 \%$ (MIDA, 2020).

Foreign investors are fleeing Malaysia amid the country's increasingly volatile in politics, which culminated in January 2021 when the Prime Minister, Tan Sri Muhyiddin Yasin resorted to emergency powers when the government lost a majority in Parliament, the first government to do so in Malaysia history. In the end of January 2021, the United Nations Conference on Trade and Development (UNCTAD) stated that foreign direct investment (FDI) into Malaysia lost by more than two-thirds to just US $\$ 2.5$ billion ( $\$ 3.34$ billion) in 2020 , the worst drop in the country due to the Covid-19 pandemic (Teoh, 2021).

\section{Literature Review}

This chapter discuss the definitions and findings of previous studies regarding Foreign Direct Investment. Besides, it is also will explain on forecasting techniques used in previous studies in forecasting Foreign Direct Investment area.

\section{Foreign Direct Investment}

Foreign Direct Investment is regarded as the ownership or control of 10 percent or more of an enterprise's voting securities or the equivalent interest in an unincorporated business (Griffin \& Pustay, 2007). Farrell (2008) defined Foreign Direct Investment as a package of capital, technology, management, and entrepreneurship, which allows a firm to operate and provide goods and services in a foreign market. From a theoretical viewpoint, Foreign Direct Investment can be divided into two categories which is Horizontal and Vertical. Horizontal FDI (HFDI) is a type of investment which is in the same industry operating abroad as a firm operate or offers the same services as it does at home and tends to produce for local or original markets only without exporting much output to host country (Maskus, 2002); (Haile \& Assefa, 2006).

Tarzi (2005) who studied Foreign Direct Investment in developing countries found that the size of the market was considered a major factor for international investors. After researching Foreign Direct Investment determinants in developed and developing countries, Chakrabarti (2001) concludes that the market size of the host country relative to per capita Gross Domestic Product (GDP) has a positive and important effect on FDI. Anyanwu (2012) found a positive link between the size of the economy and the flow of FDI to Africa, determined by the size of the urban population. Using the annual data collection, Vijayakumar, Sridharan and Rao (2010) analyzed the factors influencing the inflow of foreign direct investment into BRIC countries and found that the size of the market had a positive effect on the inflow of foreign direct investment into those countries and similar results were obtained by Ranjan and Agrawal (2001), who examined the same issue in BRIC countries.

\section{Forecasting Techniques in Foreign Direct Investment}

According to previous studies there are several forecasting techniques that been used to forecast Foreign Direct Investment in several countries. Univariate model was used which is the Autoregressive Integrated Moving Average (ARIMA) model such as the one proposed by Box, Jenkins and Reinsel in 1994 to test the relevant theories by modelling the Brazilian inward Foreign Direct Investment series in US dollars. The results confirmed the hypothesis derived from the theory, that there is a moving average model of Foreign Direct Investment inflows to Brazil, after adjusting for the detected outliers because there is a fairly dynamic series with a relatively fast value (Turolla, 2011).

Biswas (2015), used Regression Analysis, testing of Parameters, Box Jenkins methodology to build Autoregressive Integrated Moving Average (ARIMA). The objective of his study is to build a time series model and to forecast Foreign Direct Investment inflows in India over the coming period and 
have been using annual time series data for the FDI in India over the period of 1992 to 2014. In this study, accuracy and the model that been selected were tested by performing different diagnostics tests to ensure the accuracy of the results. There have been extensive forecasting models ranging from simple models to sophisticated ones. The empirical results for this study presented that Autoregressive Integrated Moving Average (ARIMA) model have shown that Foreign Direct Investment is following an increasing trend over the forecasted period which is from 2015 to 2034 (Biswas, 2015).

Dr Prasanna Perera (2015) used Autoregressive Integrated Moving Average (ARIMA) modelling to forecast FDI into the South Asian Association for Regional Cooperation (SAARC) for the period of 2013 to 2037. Dr Prasanna study applied time series data over the period of 1970 to 2012. FDI data in this study have shown stationary according to the Augmented Dickey-Fuller Test. Then researchers identify minimum $\operatorname{AIC}$ value and presents $\operatorname{ARIMA}(1,1,5)$ and $\operatorname{ARIMA}(1,0,5)$ models as optimal models to forecast Foreign Direct Investment in the region. Box-Ljung test is employed to illustrate the randomization of residuals (Perera, 2015).

Kumar and Dhingra (2012) forecast growth of FDI inflows to Sri Lanka and generated the short-term forecasts for the period of 2011 to 2020 by using SPSS (7.5). The forecasting was based on the sample data from 1990 to 2010. Their study used the Autoregressive Integrated Moving Average (ARIMA) model to evaluate the performance of FDI and compares the outcome of Sri Lanka with other South Asian countries. This study also applies Double Exponential Smoothing using Holt's approach. However, Double Exponential Smoothing model is best suited to address the type of data which exhibits either an increasing or decreasing trend over time or when the data is nonstationary in nature (Kumar et al, 2012).

Jere, Kasense and Chilyabanyama (2017), have forecasted on FDI to Zambia. There are three methods that have been considered in their paper which are Simple Exponential Smoothing (SES), Holt-Winters Exponential Smoothing (HWES) and Autoregressive Integrated Moving Average (ARIMA). In their study, they found the best fit model to forecast on Zambia's annual net FDI inflows from 1970 to 2014. The final finding showed that after a comparison of the three methods, ARIMA $(1,1,5)$ is the best fit model because it has the minimum error. Forecasting results give a gradual increase in annual net FDI inflows of about $44.36 \%$ by 2024 .

\section{Time Series Analysis}

Time Series Analysis is used to determine a good model that can be used to forecast business metrics such as stock market price, sales, turnover, and more. It allows us to understand timely patterns in data and analyze trends in business metrics. Over time the behavior of a time series can be described by characterizing certain unique attributes, which can be identified and are generally grouped into four main components types. These are trend component, the cyclical component, the seasonal component and irregular component. It has been the usual practice in classical time series analysis to segregate and to analyse the components in a systematic manner. The symbols that will be used to represent the respective components of the time series are as follow:

Let:

- $T_{t}$ represents the trend component in time period $t$,

- $C_{t}$ represents the cyclical component in time period $t$,

- $S_{t}$ represents the seasonal component in time period $t$, and

- $I_{t}$ represents the irregular component in time period $t$.

\section{The Trend Component}

The trend component in business or economic for time series data describes the general upward or downward movements that characterize all economic and business activities which usually found in dynamic economic and business environments. The trend represents the long-run growth or decline over time. Along-term increase or decrease in the data which might not be linear. Sometimes the trend 
might change direction as time increases. The simplest method to identify the trend is to plot straight line through the points on the graph (Lazim, 2020).

\section{The Cyclical Component}

The cyclical component in time series data refer to rises and falls of the series over unspecified period of time, usually around a long- run trend. The cyclical exists when data exhibit rises and falls that are not of fixed period. The average length of cycles is longer than the length of a seasonal pattern. In practice, the trend component is assumed to include the cyclical component. Sometimes the trend and cyclical components together are called as trend-cycle (Lazim, 2020).

\section{The Seasonal Component}

Seasonal component, also known as seasonal variation, characterizes regular fluctuations occurring within a specific period of time, for example within a day, a week, a month, a year and so forth. These fluctuations repeat in the periods of time with the same regulatory pattern. It exists when a series exhibits regular fluctuations based on the season. Seasonality is always of a fixed and known period (Lazim, 2020).

\section{The Irregular Component}

This last component of time series can be categorized in two different ways which either irregular or random effect. The irregular component or also known as the residual is what remains after the seasonal and trend components of a time series have been estimated and removed. It results from short term fluctuations in the series which are neither systematic nor predictable. In a highly irregular series, these fluctuations can dominate movements, which will mask the trend and seasonality (Lazim, 2020).

\section{Forecasting Method}

The data collected can be analyzed through the forecasting methods. Forecasting methods that can be consider is Simple Exponential Smoothing Model (SES), Holt's Exponential Smoothing Model (HSE), Simple Naïve and Naïve with trend, Autoregressive Integrated Moving Average (ARIMA), and Time Series Regression.

The best method of forecasting will be determined on the basis of accuracy. There are several common accuracy methods that can be used which are mean absolute percentage error (MAPE), root mean square error (RMSE) and geometric root mean square error (GRMSE). Before proceeding with all the forecasting methods, the pattern of data series needs to be determined and later will be used to forecast.

\section{Simple Exponential Smoothing Model (SES)}

The exponential smoothing method is a method that uses weighted moving average of the past data as a basis for forecast. This method requires only one parameter, the smoothing constant, $\alpha$, to generate the fitted values and hence forecast. This method maintains average demand and adjust it for each period in proportion to the difference between latest actual demand figure and latest average value (Lazim, 2020). The equation of simple exponential smoothing model denoted as:

where

$$
\hat{y}_{t+1}=\hat{y}_{t}+\alpha\left(y_{t}-\hat{y}_{t}\right)
$$

$$
\begin{aligned}
& \hat{y}_{t+1}=\text { the forecast value for next period, } \\
& \alpha=\text { smoothing constant }(0<\alpha<1) \\
& y_{t}=\text { actual value in period } \mathrm{t} \\
& \hat{y}_{t}=\text { forecast value of period } \mathrm{t}
\end{aligned}
$$




\section{Holt's Exponential Smoothing Model (HSE)}

This method is sometimes called as Holt's Exponential Smoothing, named for two contributors: Charles Holt and Peter Winters. The triple exponential smoothing method used when there are trend and seasonality in the data series. In addition, a new parameter, $\gamma$ (gamma) controls the influence on the seasonal component.

Conceptually, this methodology is similar to Brown's exponential smoothing, except that the technique smoothes the trend and the slope in the time series by using different smoothing constants (Lazim, 2020). By using this approach, the analyst gains some flexibility that is not presented when using the Brown's method. Specifically, in Brown's approach, the estimated trend values are sensitive to random influences and are not dealt with it directly, whereas in this case, selecting the smoothing constant makes it easier to track the trend and the slope (Lazim, 2020). Low values of $\alpha$ and $\beta$ should be used when there are frequent random fluctuations in the data, and high values when there is a pattern such as a linear trend in the data (Lazim, 2020). The equation for this technique is shown below where it involves two main equations.

$$
\begin{aligned}
& S_{t}=\alpha y_{t}+(1-\alpha)\left(S_{t-1}+T_{t-1}\right) \ldots \ldots 1 \\
& T_{t}=\beta\left(S_{t}-S_{t-1}\right)+(1-\beta) T_{t-1} \ldots \ldots 2
\end{aligned}
$$

where

$$
\begin{aligned}
& S=\text { smoothing value, } \\
& y=\text { time series, } \\
& b=\text { estimate of trend slope }, \quad \beta=\text { smoothing constant for trend }
\end{aligned}
$$

slope,

$$
L=\text { the period, } \quad \mathrm{\gamma}=\text { smoothing constant for }
$$

seasonal.

$$
S n=\text { estimate of the seasonal component, }
$$

\section{Naïve Methods}

Naïve method is the simplest technique and very easy to use. There were two types of naïve method which is simple naïve and naïve with trend.

\section{i. Simple Naïve}

Simple naïve forecasting is the techniques for estimate, where the actual data is used as forecasts for future without having to adjust or alter the original data. This model strongly believes that what happens today will happen again tomorrow or any other time in the future. The equation of this model used is:

$$
Y_{t+1}=Y_{t}
$$

\section{ii. Naïve with Trend}

The naïve with trend model is the modification of simple naïve with the consideration of the trend component. This model implies that all future forecasts equal as the recent actual observed value plus the growth rate, that is the trend value. This model can be used even with the fairly short time series. The equation of naïve with trend model is:

$$
F_{t+1}=y_{t} \frac{y_{t}}{y_{t-1}}
$$

Hence, if $y_{t}>y_{t-1}$ then the trend is upward while if $y_{t}<y_{t-1}$ then the trend is downward. 


\section{Autoregressive Integrated Moving Average (ARIMA)}

The Box-Jenkins approach also known as Autoregressive Integrated Moving Average (ARIMA). This approach was first introduced by George E. P. Box (University of Wisconsin, USA) and Gwilym M. Jenkins (University of Lancaster, UK) in 1976. They provided a comprehensive explanation of the technique of analysis in the time series data to be used in the univariate ARIMA models. ARIMA modelling will used previous time series data and error to forecast future values.

ARIMA required error terms and observations of lagged terms to capture complex relationships. These models depend on the arrangement of variables on past values. Incidentally, for most economics or business data series, non-stationarity is the norm. Common statistics used to identify the model type is the autocorrelation $(\mathrm{ACF})$ and the partial autocorrelation coefficients (PACF). Therefore, in order to select the best fitted model, one needs to run several models and applying certain statistical test procedures. From there, one should then be able to determine the best fitted model. There are 3 stages in ARIMA which are model identification, model estimation and validation and model application (Lazim, 2020). Thus the model obtained is represented in general term as ARIMA (p,d,q),

$$
y_{t}^{\prime}=c+\emptyset_{1} y_{t-1}^{\prime}+\cdots+\emptyset_{p} y_{t-p}^{\prime}+\theta_{1} \varepsilon_{t-1}+\theta_{q} \varepsilon_{t-q}+\varepsilon_{t}
$$

The Box-Jenkins are denoted by ARIMA $(p, d, q)$ where:

- $\quad p$ is the number of autoregressive terms

- $d$ is the number of differences and

- $q$ is the number of moving averages

The autoregressive process $(p)$. Autoregressive is the process of regressing variables at their own past values. It assumes that $Y_{t}$ is a linear function of the proceeding values. The equation for this process is:

where

$$
Y_{t}=\theta_{1} Y_{t-1}+\tau_{t}
$$

$\theta=$ linear combination of previous observations
$\tau=$ random component of each observation

The integrated process $(d)$. Integrated is a property that eliminates seasonality in a time series. The archetype of the nonstationary series is the process of integrated. The difference of order 1 assumes that the difference between the two successive values of $Y$ is constant. The equation of integrated process is denoted as:

$$
Y_{t}=Y_{t-1}+\tau_{t}
$$

The moving average process $(q)$. The moving average eliminates random movements from time series. This process order indicates that the number of previous periods embedded in the current value. Equation for moving average process is:

$$
Y_{t}=\tau_{t}-\theta_{1} \tau_{t-1}
$$

The assumptions of ARIMA model is the data is stationarity data. If the data is non-stationary, we need to transform the data before using the ARIMA model.

\section{Time Series Regression}

The basic concept to forecast the time series of interest is by assuming $y$ has a linear relationship with other time series $x$. This is what econometricians call a dynamic causal effect (Lazim, 2020). The forecast variable $y$ is sometimes also called the regress and, dependent or explained variable. 
The predictor variables $x$ is sometimes also known as the regressors, independent or explanatory variables (Lazim, 2020). Curve estimation will help in identifying the best fit.

$$
\begin{gathered}
y_{t}=T R+\varepsilon_{t} \\
y_{t}=B_{0}+B_{1} t+B_{2} t^{2}+B_{3} t^{3}+\varepsilon_{t}
\end{gathered}
$$

\section{Conclusion}

Based on the summary of existing literature, this paper briefly discussed the studies of Foreign Direct Investment and also the forecasting techniques used in previous studies. Time Series Analysis is used to determine a good model in order to help in forecasting data. The forecasting techniques that can be considered are Simple Exponential Smoothing (SES), Holt's Exponential Smoothing Model (HES), Simple Naïve and Naïve with trend, Autoregressive Integrated Moving Average (ARIMA), and Time Series Regression.

\section{References}

Alam, A. \&. Shah, S.Z.A. (2013). Determinants of foreign direct investment in OECD member countries, Journal of Economic Studies, 40(4), 515 - 527.

Antonakakis, N. \& Tondl, G. (2012). Do determinants of FDI to developing countries differ among OECD countries? Insights from a Bayesian Panel Data Approach. Vienna University of Economics and Business Draft working paper. pp 42.

Asiedu, E. (2006). Foreign Direct Investment in Africa: The Role of Natural Resources, Market Size, Government Policy, Institutions and Political Instability. The World Economy, 29(1), 63-77.

Biswas, A. (2015). Forecasting Net Foreign Direct Investment Inflows in India: Box-Jenkins ARIMA Model. International Journal of Management and Business Studies, 4(3), 49-58.

Denisia, V. (2010). Foreign Direct Investment Theories: Overview of the Main FDI Theories. European Journal of Interdisciplinary Studies, 2(2), 89-114.

Jere, S., Kasense, B., \& Chilyabanyama, O. (2017). Forecasting Foreign Direct Investment to Zambia: A Time Seris Analysis. Open Journal of Statistics, 7(1).

Jones, R. (1980). Maximum Likelihood Fitting of ARMA Models to Time Series with Missing Observations. Technometrics, 22(3), 389-395. doi:10.2307/1268324

Kandiero, T. \& Chitiga, M. (2014). Trade openness and foreign direct investment in Africa. South African Journal of Economic and Management Sciences, 9(3), 355.

Kalam, Khaled. (2018). Foreign Direct Investment Determinants in Malaysia. British Journal of Business Design \& Education, 11(1).

Kumar, G. \& Dhingra, N. (2012). Growth performance and forecasts of FDI inflows to Sri Lanka. E3 Journal of Business Management and Economics, 3(8), 307-317.

Lazim, M.A. (2020). Introductory business forecasting: A practical approach ( $3^{\text {rd }}$ ed.). UiTM Press.

Mohamed S. and Sidiropoulos, M. (2010). Another look at the determinants of foreign direct investment in MENA countries: An empirical investigation. Journal of Economic Development, 35(2), 75-95.

Perera, P. (2015). Modeling and Forecasting Foreign Direct Investment (FDI) into SAARC for the period of 2013-2037 with ARIMA. International Journal of Business and Social Science, 6(2), 264-272.

Teoh, S. (2021, February 4). Foreign Direct Investment into Malaysia Plunge, experts citegrowing Political Risk. Retrieved from https://www.straitstimes.com/asia/se-asia/foreign-directinvestments-into-malaysia-plunge-experts-cite-growing-political-risk

Vijayakumar, N., Sridharan, P. and Rao, K. (2010). Determinants of FDI in BRICS countries: A panel analysis. International Journal of Business Science and Applied Management, 5(3), 1- 13. 